\title{
The Combination of VIP and Atropine Induces REM Sleep in Cats Rendered Insomniac by PCPA
}

Oscar Prospero-García, M.D., Ph.D., Anabel Jiménez-Anguiano, M.Sc., and René Drucker-Colín, Ph.D.

Twenty-four cats were implanted with electrodes for chronic sleep recordings. One week after the surgery, ats were treated with two intraperitoneal injections of parachlorophenylalanine ( $P C P A)$, an inhibitor of serotonin synthesis, to induce insomnia. Twenty-four hours after the second injection of PCPA, cats were at the peak of insomnia (strong reduction of both slow wave sleep 2 and rapid-eye movement [REM] sleep). During this period cats were divided into four groups $(n=6)$ and were injected with either atropine $(0.5 \mathrm{mg} / \mathrm{kg}, I M$
[3.5 mmol/kg]), vasoactive intestinal peptide (VIP) (200 ng, ICV [60 pmol]) or atropine plus VIP (same doses and routes of administration). The control group received saline intramuscularly (IM) intracerebroventricularly and (ICV). Results showed that VIP and atropine injected alone and in combination increased mean total time of REM sleep in $P C P A$-treated animals. These findings are discussed in terms of a serotonin-acetylcholine interaction. [Neuropsychopharmacology 8:387-390, 1993]
KEY WORDS: REM sleep; Insomnia; Vasoactive intestinal polypeptide; Atropine; Serotonin; PCPA

Acetylcholine $(\mathrm{ACh})$ is one of the neurotransmitters associated with rapid-eye-movement (REM) sleep generation.

administration of cholinergic agonists into the pontine reticular formation (PRF) of cats and rats promptly induces REM sleep (for extensive review, see Shiromani et al. 1987; Hobson 1990). An increase in ACh release associated with REM sleep has also been observed in several brain structures, including the PRF (for review, see Gillin and Shiromani, 1990). Recently, VelazquezMoctezuma et al. (1989) have reported evidence suggesting that the $\mathrm{M} 2$ cholinergic receptors are more critical in inducing this effect. However, M1 receptors may

From the Departmento de Neurociencias, Instituto de Fisiología Celular, Universidad Nacional Autónoma de México

Address correspondence to: Dr. Oscar Prospero-García, Dept. of Neuropharmacology CVN-13, The Scripps Research Institute, 10666 North Torrey Pines Rd., La Jolla, CA 92037.

Received September 15, 1992; revised November 24, 1992; accepted December 28, 1992. also play an important role in the generation of REM sleep (Salín-Pascual et al. 1992).

On the other hand, vasoactive intestinal polypeptide (VIP) is also a potent REM sleep inducer. For example, intracerebroventricular administration of VIP in normal rats, cats, and rabbits increases REM sleep (Riou et al. 1982; Drucker-Colín et al. 1984; Obal et al. 1989). In addition, VIP restores REM sleep in parachlorophenylalanine (PCPA)-treated insomniac rats (Riou et al. 1982) and cats (Prospero-García et al. 1986). Moreover, the inactivation of the endogenous VIP by its antagonists (Mirmiran et al. 1988) or antibodies anti-VIP (Riou et al. 1982; Drucker-Colín et al. 1988) reduce REM sleep.

From a functional viewpoint, $\mathrm{ACh}$ and VIP are closely related. Both substances coexist in the same terminals and one modulates the release of the other (Lapchak and Beaudet 1990; Wang et al. 1986; for extensive review, see Whittaker 1989; Magistretti 1990). Moreover, VIP may enhance the synthesis of ACh in structures like the hippocampus (Luini et al. 1984).

Due to this interaction, we have investigated 
whether VIP's REM sleep-inducing effect in PCPAtreated insomniac cats depends on cholinergic mechanisms. Earlier observations showed that carbachol, a cholinergic agonist, did not induce REM sleep in PCPAtreated cats when administered into the PRF (DruckerColín and Prospero-García 1988). However, it reduces the REM sleep-inducing effect of VIP by approximately $50 \%$ when both compounds are administered simultaneously (Drucker-Colín et al. 1988). These findings suggested that in PCPA-treated cats, the insomnia observed may be a result of the reduction in serotonin availability associated with an overactivation of the cholinergic system. To further our understanding of ACh-VIP-serotonin interaction in REM sleep induction, we decided to test the effect of atropine, VIP, and the combination of both in the sleep of PCPA-treated insomniac cats.

Twenty-four adult male and female cats weighing 2.5 to $3.5 \mathrm{~kg}$ were implanted, under pentobarbital anesthesia, with a set of electrodes for chronic recordings. Two screw electrodes were placed on the parietal bones for electroencephalographic (EEG) recording and two other electrodes were placed in the internal and external canthus of the orbit to record eye movements (EOG). Postural tone was recorded through two wire electrodes inserted in the muscles of the neck. An additional tripolar electrode placed into the lateral geniculate body recorded ponto-geniculo-occipital (PGO) spikes. A stainless-steel guide cannula was aimed to the fourth ventricle for the administration of VIP. During the surgery, the position of the cannula's tip into the fourth ventricle was corroborated withdrawing cerebrospinal fluid (CSF). In this position, the cannula was anchored to the skull with dental cement. A stylet was placed into the cannula to avoid CSF outflow. Male and female cats were housed separately in two rooms. Dimensions of both rooms were approximately $35 \times$ $2 \mathrm{~m}$. Light-dark cycle was controlled(12:12). Lights were turned on at 8:00 AM.

One week after the surgery cats were habituated to the recording conditions for 24 hours. Upon completion of the habituation period, cats were treated twice with $400 \mathrm{mg} / \mathrm{kg}(0.4 \mathrm{~mol} / \mathrm{kg})$ of PCPA. The two intraperitoneal injections were separated by a 24-hour period. Twenty-four hours after the second injection cats were divided into four groups $(n=6)$. and were challenged with either saline (ICV and IM), atropine $(0.5 \mathrm{mg} / \mathrm{kg}$ IM [ $3.5 \mathrm{mmol} / \mathrm{kg}$ ]), VIP (200 ng ICV [60 pmol]) or atropine plus VIP. Three cats in the control group received saline into the fourth ventricle, whereas the other three received saline intramuscularly. Since saline administered through either route did not modify the insomnia induced by PCPA, the six cats were analyzed together as a single group. Immediately after the injection, cats were recorded in a sound-attenuated, Faraday chamber (8:30 AM to 7:30 PM). Four cats (one from each group) were simultaneously recorded and constantly monitored through closed circuit television.

Sleep recordings were visually scored and four sleep states were determined according to standard criteria (Ursin and Sterman, 1981). Data were analyzed on the basis of total time in minutes of wakefulness, slow-wave sleep 1 (SWS1), slow-wave sleep 2 (SWS2), and REM sleep. Data were presented as percent of controls for each sleep stage. Frequency and duration of the individual periods of REM sleep were also analyzed. Statistical analysis of the results was carried out using an analysis of variance and then a Scheffé test (Scheffé, 1953).

The results summarized in Fig. 1 and Table 1 show that PCPA-treated cats receiving saline spent more than $80 \%$ of the total time of recording in wakefulness. Both VIP alone and atropine in combination with VIP reduced wakefulness induced by PCPA by approximately $40 \%(p<.01)$, whereas atropine alone reduced wakefulness by approximately $30 \%(p<.01)$. Vasoactive intestinal peptide alone and in combination with atropine increased SWS1 by approximately $150 \%$, whereas atropine alone increased SWS1 by approximately $85 \%(p<$ .01 ). Rapid-eye movement sleep was increased by approximately $800 \%$ when VIP or atropine was injected alone, whereas the combination of these compounds increased REM sleep by about $1300 \%(p<.001)$. Slowwave sleep 2 was not significantly increased by any of the drugs tested.

Vasoactive intestinal peptide and atropine alone and in combination augmented the total time of REM sleep, increasing the frequency of appearance and duration of this sleep stage $(p<.01)$.

Another interesting result was that atropine and VIP alone and in combination reduced PGO activity during wakefulness and SWS1, but not during REM sleep. Such an effect was observed at the end of the first hour and lasted for the rest of the recording period. No further quantification of this signal was performed in this study.

These results show that both atropine and VIP are able to induce REM sleep in cats rendered insomniac by PCPA. It is also interesting that VIP potentiates atropine effects. We have previously observed that atropine $(0.5 \mathrm{mg} / \mathrm{kg})$ and VIP $(200 \mathrm{ng})$ reduce REM sleep in normal cats (Prospero-García, 1989); thus, the induction of REM sleep in PCPA-treated cats may be dependent on the reduction of serotoninergic neurotransmission.

It has been suggested that serotonin and $\mathrm{ACh}$ interact to regulate SWS-REM sleep generation (Hobson, 1990). It is likely that a reduction in the activity of the serotoninergic system may disinhibit the cholinergic system within the dorsal tegmentum as has been suggested by in vitro studies (Luebke et al. 1992). Because ACh also facilities arousal, the resulting overactivation of the cholinergic system may account for the induc- 

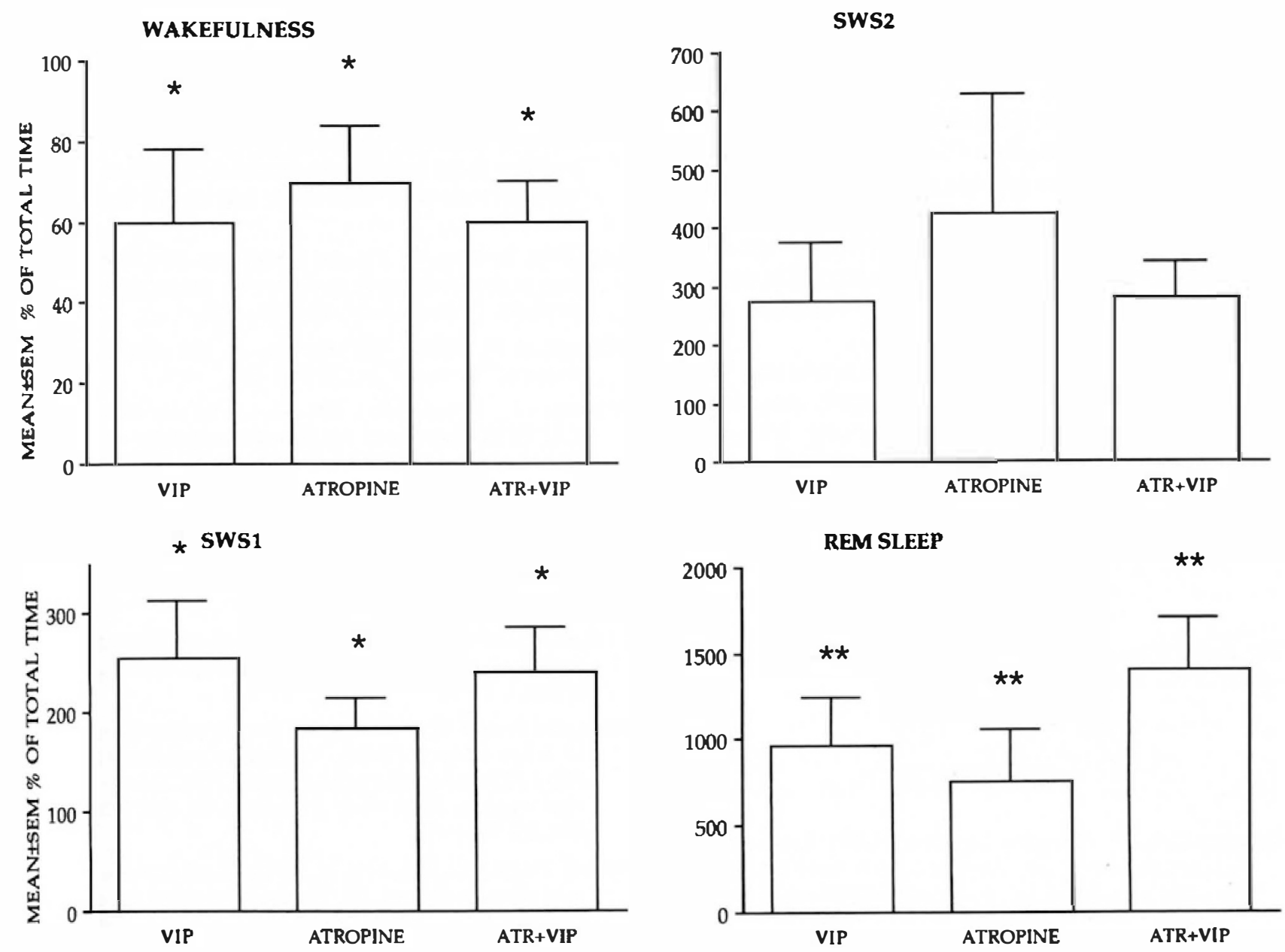

Figure 1. Atropine alone and in combination with VIP increases both SWS1 and REM sleep in PCPA-treated cats. Their main effect is exerted on REM sleep. Data are presented as percent of controls (100\% is the effect of saline). ATRO + VIP: atropine plus VIP; Wakefulness: $F=6.475, d f=3,20, p<.01$. SWS1: $F=3.563, d f=3,20, p<.01$. SWS2: $F=1.784$, $d f=3,20, p=.18$; REM: $F=5.185, d f=3,20, p<.001$ as compared to saline.

tion of insomnia. For instance, it has been shown that physostigmine, an indirect cholinergic agonist, elicits either wakefulness or REM sleep, depending on the dose and when it is administered during SWS (Gillin et al.1978). Similar results have been obtained with the

Table 1. Effect of Atropine or VIP and Their Combination on REM Sleep Parameters of PCPA-Treated Insomniac Cats

\begin{tabular}{lccc}
\hline & Frequency & Duration & Latency \\
\hline Saline & $3.16 \pm 3$ & $0.5 \pm 0.2$ & $510 \pm 103$ \\
VIP & $14 \pm 1.8^{\star \star}$ & $2.5 \pm 0.7^{\star}$ & $97.2 \pm 26.7^{\star \star}$ \\
Atropine & $8.5 \pm 4^{\star}$ & $2.9 \pm 0.8^{\star}$ & $299.4 \pm 109^{\star}$ \\
Atro + VIP & $17.5 \pm 5^{\star \star}$ & $3.01 \pm 0.6^{\star}$ & $108.5 \pm 91.5^{\star \star}$ \\
\hline
\end{tabular}

Values represent Mean \pm SEM in minutes for duration and latency; for frequency the number of episodes during 11 hours of recording. Frequency: $F=4.006, d f=3,20, p<.01$; duration: $F=4.074$, $d f=3,20, p<.01$; latency: $F=5.006, d f=3,20, p<.001$ as compared to saline.

${ }^{\star} p<.01$.

$* p<.001$. iontophoretical administration of carbachol and physostigmine into the pons of unanesthetized headrestrained cats (López-Rodríguez'et al. 1992). In this context, the administration of cholinergic agonists like carbachol in PCPA-treated insomniac cats, potentiates ACh activity, thereby facilitating insomnia instead of REM sleep (Drucker-Colín and Prospero-García 1988). In contrast, by reducing the activity of the cholinergic system atropine may be reestablishing a balance between serotonin and $\mathrm{ACh}$, thereby eliciting REM sleep.

In addition, it is known that VIP exerts inhibitory or facilitatory effects on $\mathrm{ACh}$ release depending on its concentration (see Whittaker 1989). Such a dosedependent effect is also observed on REM sleep. For example, $100 \mathrm{ng}$ of VIP (ICV) enhance REM sleep, whereas 200 ng reduce it in normal cats (Drucker-Colín et al. 1984; Prospero-García 1989). In contrast, in PCPAtreated cats, $100 \mathrm{ng}$ of VIP does not restore REM sleep, whereas $200 \mathrm{ng}$ restores it. In addition, when VIP is injected in combination with atropine, REM sleep is potentiated. 
We have previously shown that carbachol does not induce REM sleep in PCPA-treated cats (Drucker-Colín and Prospero-García 1988). The present results show that atropine induces REM sleep. Therefore, it is likely that insomnia observed in PCPA-treated cats may be due in part to an overactivation of the cholinergic system. In addition, since VIP $(200 \mathrm{ng})$ reduces REM sleep in normal cats (Prospero-García, 1989) and has synergistic effects with atropine in inducing REM sleep in PCPA cats, it may be that at this concentration, VIP is antagonizing cholinergic activity.

In conclusion, the property of atropine and VIP to induce REM sleep in PCPA-treated cats, may depend on the reduction of serotoninergic activity. Ultimately, REM sleep generation may depend on a balance between serotonin and $\mathrm{ACh}$ in normal conditions.

\section{ACKNOWLEDGMENT}

The authors are grateful to Dr. Patricia Robledo for her critical review of the manuscript.

\section{REFERENCES}

Drucker-Colín R. Prospero-García O (1988): Microinjection of carbachol into the pontine area is unable to modify insomnia induced by p-chlorophenylalanine (PCPA). Brain Res 462:163-166

Drucker-Colín R, Bemal-Pedraza J, Femández-Cancino F, Oksenberg A (1984): Is vasoactive intestinal polypeptide (VIP) a sleep factor? Brain Res 278:308-312

Drucker-Colín R, Prospero-García O, Arankowsky-Sandoval G, Pérez-Montfort R (1988): Gastropancreatic peptides and sensory stimuli as REM sleep factors. In Inoué $S$, Schneider-Helmert D (eds), Sleep Peptides: Basic and Clinical Approaches. Tokyo: Japan Sci. Soc. Press/Berlin: Springer-Verlag, pp 73-94

Gillin JC, Shiromani P (1990): Cholinergic mechanisms in sleep: Basic and clinical applications. In Montplaisir J, Godbout R (eds), Sleep and Biological Rhythms. New York: Oxford University Press, pp 186-208

Gillin JC, Sitaram N, Duncan WC (1978): Physostigmine alters onset but not duration of REM sleep in man. Psychopharmacology 58:111-114

Hobson JA (1990): Sleep and dreaming. JNeurosci10:371-382

Lapchak PA, Beaudet A (1990): Cholinergic regulation of vasoactive intestinal peptide content and release in rat frontal cortex and hippocampus. J Neurochem 55:13401345

López-Rodríguez F, Kohlmeier K, Morales FR, Chase MH (1992): The injection of cholinergic drugs into the same site in the brainstem reticular formation results in different responses which depend on the animal's prior behavioral state. Neurosci Abstr 1:880

Luebke JI, Greene RW, SembaK, Kamondi A, McCarley RW, Reiner PB (1992): Serotonin hyperpolarizes cholinergic low threshold burst neurons in the rat laterodorsal tegmental nucleus in vitro. Proc Natl Acad Sci USA 89: 743-747

Luini VN, Rostene W, Rhodes J, McEwen BS (1984): Activation of choline acetyltransferase by vasoactive intestinal peptide. J Neurochem 42:1131-1134

Magistretti PJ (1990): VIP neurons in the cerebral cortex. Trends Pharmacol Sci 11:250-254

Mirmiran M, Kruisbrink J, Bos NPA, Van der Werf D, Boer GJ (1988): Decrese of rapid-eye-movement sleep in the light by intraventricular application of a VIP-antagonist in the rat. Brain Res 458:192-194

Obal F Jr, Opp M, Cady BC, Johannsen L, Krueger JM (1989): Prolactin, vasoactive intestinal peptide, and peptide histidine methionine elicit selective increases in REM sleep in rabbits. Brain Res 490:292-300

Prospero-García O (1989): Papel de los peptidos gastropancreaticos en la modulación del sueño. Doctoral thesis. México, D. F.

Prospero-García O, Morales M, Arankowsky-Sandoval G, Drucker-Colín R (1986): Vasoactive intestinal polypeptide (VIP) and cerebrospinal fluid (CSF) of sleep deprived cats restores REM sleep in insomniac recipients. Brain Res 385:169-173

Riou F, Cespuglio R, Jouvet M (1982): Endogenous peptides and sleep in the rat. III. The hyponogenic properties of vasoactive intestinal polypeptide. Neuropeptides 2 : 265-277

Salín-Pascual R, Granados-Fuentes D, Galicia-Polo L, Nieves E, Roehrs T, Roth T (1992): Biperiden administration during REM sleep deprivation diminished the frequency of REM sleep attemps. Sleep 15:252-256

Scheffé H (1953): A method for judging all contrasts in the analysis of variance. Biometrika 40:87-104

Shiromani P, Gillin JC, Henriksen SJ (1987): Acetylcholine and the regulation of REM sleep: Basic mechanisms and clinical implications for affective illness and narcolepsy. Annu Rev Pharmacol Toxicol 27:137-156

Ursin R, Sterman MB (1981): A Manual for Standard Scoring of Sleep and Waking States in Adult Cat. Los Angeles, CA: UCLA Publication Services

Velazquez-Moctezuma J, Gillin JC, ShiromaniP (1989): Effect of specific M1, M2 muscarinic receptor agonists on REM sleep generation. Brain Res 503:128-131

Wang JY, Yaksh TL, Harty GJ, Go VLW (1986): Neurotransmitter modulation of VIP release from cat cerebral cortex. Am J Physiol 250:R104-R111

Whittaker VP (1989): Vasoactive intestinal polypeptide (VIP) as cholinergic co-transmitter: Some recent results. Cell Biol Intl Rep 13:1039-1051 